\title{
NOTES
}

\section{Aldol Addition of Dimethylsilyl Enolate in the Presence of Polyisocyanate with Alkali Metal Salt Catalyst}

\author{
Shin-ichi YAmamoto, Yusuke AIZAwa, and Osamu MoriYA ${ }^{\dagger}$ \\ Department of Applied Chemistry, National Defense Academy, \\ 1-10-20 Hashirimizu, Yokosuka 239-8686, Japan
}

(Received July 20, 2004; Accepted October 4, 2004; Published January 15, 2005)

KEY WORDS Polyisocyanate / Aldol Addition / Solid Solvent / Reaction Envionment / [DOI 10.1295/polymj.37.47]

The polymers containing the aprotic polar solvent structures such as DMF, DMAc, and DMSO have been employed as the additives for several nucleophilic substitution reactions. ${ }^{1-6}$ These polymers, called "solid co-solvent", have been used with alkali metal bases and alkylhalide nucleophiles in two phases reaction system of organic solvent and water. In the works, the main role of the solid solvents is regarded as an effective phase-transfer agent. In addition, it has been pointed that the solid solvent provides a good reaction environment to enhance the substitution reactions by the effects of the polar solvent structure and hydrophobic main chain. Such previous findings suggest that the polymeric solvents possess the possibility to be utilized as the solvent itself and enable a solventfree reaction. The use of the solid solvents is preferable in the view of environmental problem and, further, the solid solvents are reusable. Consequently, the reaction system utilizing the solid solvents is thought to be an interesting ecological methodology.

On the basis of the consideration mentioned above, we reported recently the effects of the solid $\operatorname{poly}(N, N$ dimethylacrylamide), as the analog of DMF, on the alkali metal salt catalyzed aldol addition of dimethylsilyl (DMS) enolate to aldehyde. ${ }^{7}$ In the work, the solvent structure in the polyacrylamide gel was demonstrated to be effective for holding an alkali metal salt and provide the reaction environment to give the corresponding aldol products in good yields. The results were comparable with those obtained in DMF solution by the use of analogous catalysts, which was reported previously by Hosomi et al. ${ }^{8}$ In the examinations using the several kinds of the polyacrylamide gels, the derivative of Wang resin (PDMA), which was assumed to contain more flexible polyacrylamide chain, was found to be more suitable than the traditional cross-linked gel (PDMAG) for the aldol reaction (Scheme 1). In line with the obtained information, several polymeric solid solvents derived from Wang resin have been newly prepared and applied to the efficient aldol reaction catalyzed by alkali metal salts. In this work, we employ polybutylisocyanate (PBI) as the solid solvent, which has been prepared from Wang resin bounded pyrrolidine derivative according to the procedure reported by Okamoto et al. (Scheme 2) ${ }^{17}$ The polyisocyanate PBI is also consisted of amide groups as the main chain and, further, assumed to be a kind of asymmetric polymer. Therefore, the use of PBI is expected to show several characteristics such as the effective holding of alkali metal salts and the possibility of stereoselective reaction.

\section{EXPERIMENTAL}

\section{General}

${ }^{1} \mathrm{H}$ and ${ }^{13} \mathrm{C}$ NMR spectra were recorded on either a Bruker DMX-500 or a JEOL AL-300 spectrometer, using tetramethylsilane (TMS) as an internal standard in chloroform- $d\left(\mathrm{CDCl}_{3}\right)$. IR spectra were recorded on a Jasco FT/IR-230 spectrometer. The number-average molecular weight $\left(M_{\mathrm{n}}\right)$ and polydispersity $\left(M_{\mathrm{w}} / M_{\mathrm{n}}\right)$ were estimated on a Tosoh HPLC-8220 system with refractive index (RI) and ultraviolet (UV, $\lambda=254$ $\mathrm{nm}$ ) detectors and a consecutive column (TSKgel Super $\mathrm{HM}-\mathrm{H}$ ) by using a calibration curve of polystyrene standards. As an eluent, chloroform $\left(\mathrm{CHCl}_{3}\right)$ was used at $40^{\circ} \mathrm{C}$, the flow rate of which was adjusted to be $0.6 \mathrm{~mL} / \mathrm{min}$. Optical rotation was mesured by a Jasco P-1030 polarimeter.

Unless stated otherwise, all the chemicals and reagents were obtained commercially and used without further purification. Wang resin (100-200 mesh, 2\% DVB, loading of $\mathrm{OH}$ group: $0.88 \mathrm{mmol}$ equiv/g) was

${ }^{\dagger}$ To whom correspondence should be addressed (E-mail: moriyaos@nda.ac.jp). 
<smiles>CN(C)C(=O)C(CC(C)(C)C(=O)OCc1ccc(-c2ccccc2)cc1)C(C)(C)Br</smiles>

PDMA

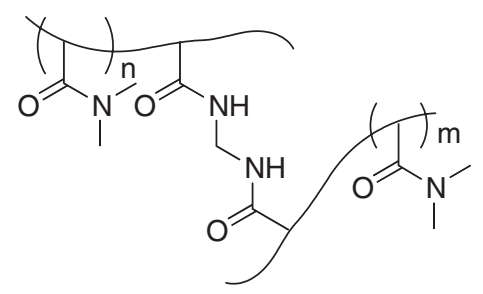

PDMAG

Scheme 1.

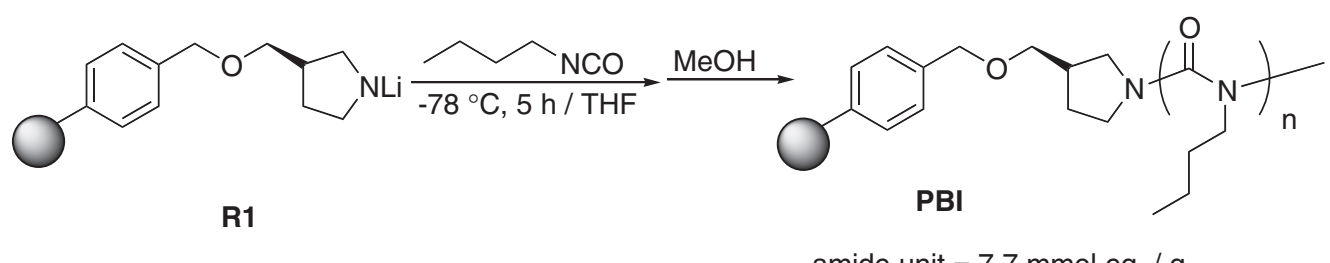

amide unit $=7.7 \mathrm{mmol}$ eq. $/ \mathrm{g}$

Scheme 2.

used as received from Novabiochem. Butylisocyanate and aldehydes were distilled over $\mathrm{CaH}_{2}$. THF and toluene were distilled from sodium-benzophenone ketyl before use. Dimethylsilyl enolates, $\mathbf{1 a},{ }^{8} \mathbf{1 b},{ }^{8}$ $\mathbf{1 c},{ }^{9}$ and $\mathbf{1 d},{ }^{9}$ and pyrrolidine functionalized Wang resin $(\mathbf{R} 1)^{10}$ were prepared acorrding to the previous reports.

\section{Preparation of $\boldsymbol{P B I}$}

R1 having $0.73 \mathrm{mmol}$ equiv/g of pyrrolidine unit $(1.40 \mathrm{~g}, 1 \mathrm{mmol})$ in toluene $(1 \mathrm{~mL})$ was fed in the round bottom flask equipped three ways stopped cock. The toluene solution of $t$-BuLi $(1.46 \mathrm{M}, 0.68 \mathrm{~mL}$, $1 \mathrm{mmol}$ ) was added to the above suspension under argon atmosphere and the mixture was stirred for $10 \mathrm{~min}$ at room temperature. The reaction mixture was diluted with THF $(100 \mathrm{~mL})$, and cooled at $-78^{\circ} \mathrm{C}$. Butylisocyanate $(11 \mathrm{~mL}, 100 \mathrm{mmol})$ was added to the THF solution in the flask via syringe. After the reaction was continued for $5 \mathrm{~h}$, the resulting mixture was added to $\mathrm{MeOH}(5 \mathrm{~mL})$, and stirred for $1 \mathrm{~h}$ at $-78^{\circ} \mathrm{C}$. After filtration, the residue was suspended in $\mathrm{CHCl}_{3}$ $(200 \mathrm{~mL})$ to dissolve unsupported polymer. The insoluble resin, collected by filtration, was washed with $\mathrm{DMF}$ and $\mathrm{MeOH}$, and dried in vacuo: Yield = $6.20 \mathrm{~g}$ (amide unit was $7.70 \mathrm{mmol}$ equiv/g). IR (KBr): 2960, $1700(\mathrm{C}=\mathrm{O}), 1348,1084(\mathrm{C}-\mathrm{O}) \mathrm{cm}^{-1}$. $M_{\mathrm{n}}$ and $M_{\mathrm{w}} / M_{\mathrm{n}}$ were estimated by size exclusion chromatography (SEC) using polystyrene standards after the cleavage of polyisocyanate from PBI by trifluoroacetic acid in $\mathrm{CHCl}_{3}(\mathrm{v} / \mathrm{v}=1 / 5)$, which was conducted for $30 \mathrm{~min}$ at room temperature. The specific rotation of the polyisocyanate was measured in $\mathrm{CHCl}_{3}$ at $20^{\circ} \mathrm{C}:[\alpha]^{25}{ }_{365}=-5^{\circ}, M_{\mathrm{n}}=20200, M_{\mathrm{w}} /$ $M_{\mathrm{n}}=1.56 . \quad{ }^{1} \mathrm{H}$ NMR $\quad\left(\mathrm{CDCl}_{3}\right) \quad \delta \quad 0.87-0.92 \quad(\mathrm{~m}$,
$-\mathrm{CH}_{3}$ ), 1.30 (br, $-\mathrm{CH}_{2}-\mathrm{C}$ ), 1.59 (br, $-\mathrm{CH}_{2}-\mathrm{C}$ ), 3.20$3.32\left(\mathrm{~m},-\mathrm{CH}_{2}-\mathrm{N}\right), 3.68-3.87\left(\mathrm{~m},-\mathrm{CH}_{2}-\mathrm{N},>\mathrm{CH}\right)$ ppm. ${ }^{13} \mathrm{C}$ NMR $\left(\mathrm{CDCl}_{3}\right) \delta 14.1,20.4,30.4,41.2$, 47.3, 55.9, $157.9 \mathrm{ppm}$.

General Procedure of Aldol Addition of Dimethylsilyl Enolate with Aldehyde

$\mathrm{LiBr}(5.2 \mathrm{mg}, 0.06 \mathrm{mmol})$ was added to a solution of PBI ( $0.09 \mathrm{~g}, 0.63 \mathrm{mmol}$ equiv of amide unit) in methanol $(5 \mathrm{~mL})$. The suspension was stirred for $15 \mathrm{~min}$, and then methanol was evaporated under reduced pressure. The residual solid was dried in vacuo (ca. 0.5 Torr) at $60^{\circ} \mathrm{C}$ for $2 \mathrm{~h}$. After cooling, dimethylsilyl enolate $(1,1.00 \mathrm{mmol})$ and aldehyde $(0.50 \mathrm{mmol})$ were added to the mixture of $\mathrm{LiBr}$ and $\mathbf{P B I}$ under argon atmosphere and heated at $40^{\circ} \mathrm{C}$ or $60^{\circ} \mathrm{C}$ for $24 \mathrm{~h}$. After the reaction, the mixture was diluted with dichloromethane $(10 \mathrm{~mL})$ and the insoluble solid was filtrated off. The filtrate was concentrated by a rotary evaporator and the residue was treated with aq $1 \mathrm{~N} \mathrm{HCl}(1 \mathrm{~mL})$ in THF $(5 \mathrm{~mL})$ at room temperature for $30 \mathrm{~min}$. The aliquot solution was extracted with ether $(30 \mathrm{~mL})$ and the organic layer was washed with brine. After drying with anhydrous $\mathrm{MgSO}_{4}$, the solvent was removed under reduced pressure. The residue was purified by column chromatography on silica gel to obtain the aldol product (2). Spectroscopic data of the products (2a,${ }^{11}$ $\mathbf{2 b},{ }^{11} \mathbf{2 c},{ }^{12} \mathbf{2 d},{ }^{13} \mathbf{2 e},{ }^{14} \mathbf{2 f},{ }^{15} \mathbf{2 g},{ }^{11}$ and $\left.\mathbf{2 h},{ }^{16}\right)$ are consistent with those reported in the previous literature. ${ }^{11}$

\section{RESULTS AND DISCUSSION}

The solid solvent PBI was thought to be an asymmetric polymer, because the polybutylisocyanate was prepared by the use of optical active pyrrolidine 


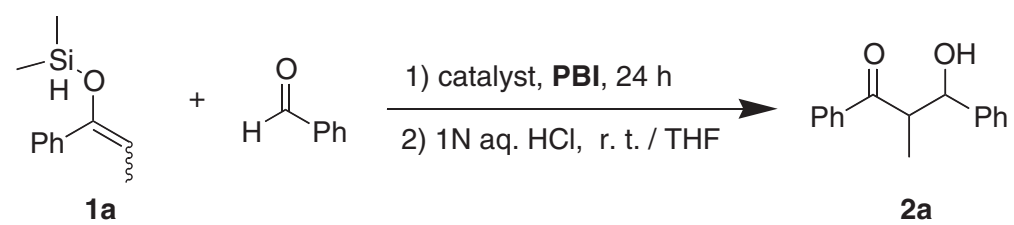

Scheme 3.

Table I. Aldol additions of 1a with benzaldehyde in the Presence of $\mathbf{P B I} \mathbf{I}^{\mathrm{a}}$

\begin{tabular}{|c|c|c|c|c|c|c|}
\hline Entry & Catalyst & $\begin{array}{l}\text { [Amide unit }] \\
\text { /[Catalyst }]\end{array}$ & $\begin{array}{c}{[\mathbf{1 a}] /} \\
\text { [benzaldehyde] }\end{array}$ & $\begin{array}{l}\text { Temp. } \\
\left({ }^{\circ} \mathrm{C}\right)\end{array}$ & $\begin{array}{l}\text { Yield } \\
(\%)\end{array}$ & syn:anti ${ }^{\mathrm{b}}$ \\
\hline 1 & $\operatorname{LiBr}(25)$ & 0 & 2 & 40 & 13 & $51: 49$ \\
\hline 2 & $\operatorname{LiBr}(25)$ & 10 & 2 & 40 & 98 & $65: 35$ \\
\hline 3 & - & $-^{c}$ & 2 & 40 & 10 & $59: 41$ \\
\hline 4 & $\operatorname{LiBr}(12)$ & 10 & 2 & 40 & 98 & $63: 37$ \\
\hline 5 & $\mathrm{LiBr}(5)$ & 10 & 2 & 40 & 15 & $65: 35$ \\
\hline 6 & $\operatorname{LiBr}(5)$ & 20 & 2 & 40 & 20 & $62: 38$ \\
\hline 7 & $\mathrm{LiBr}(12)$ & 10 & 1 & 40 & 36 & $57: 43$ \\
\hline 8 & $\operatorname{LiBr}(12)$ & 10 & 2 & 20 & 31 & $64: 36$ \\
\hline 9 & $\operatorname{LiBr}(12)$ & 10 & 2 & 40 & 32 & $59: 41$ \\
\hline 10 & $\operatorname{LiBr}(12)$ & 10 & 2 & 40 & 28 & $57: 43$ \\
\hline 11 & $\mathrm{MgCl}_{2}(12)$ & 10 & 2 & 40 & 73 & $37: 63$ \\
\hline 12 & $\mathrm{MgCl}_{2}(12)$ & 0 & 2 & 40 & 42 & $61: 39$ \\
\hline 13 & $\mathrm{CaCl}_{2}(12)$ & 10 & 2 & 40 & 13 & $56: 44$ \\
\hline 14 & $\mathrm{ZnBr}_{2}(12)$ & 10 & 2 & 40 & 92 & $56: 44$ \\
\hline 15 & $\mathrm{ZnBr}_{2}(12)$ & 0 & 2 & 40 & 94 & $52: 48$ \\
\hline
\end{tabular}

${ }^{\mathrm{a}}$ Conditions: $0.5 \mathrm{mmol}$ of benzaldehyde for $24 \mathrm{~h}$. ${ }^{\mathrm{b}}$ Determined by ${ }^{1} \mathrm{H}$ NMR. ${ }^{\mathrm{c}} 0.63 \mathrm{mmol}$ equiv of amide unit ([amide unit]/[benzaldehyde] $=1.25$ ).

group bounded on Wang resin modified Okamoto et al.'s procedure (Scheme 2). ${ }^{17}$ The polyisocyanate chain incorporated into the resin under anionic conditions was analyzed after the cleavage by trifluoracetic acid. The $M_{\mathrm{n}}$ and $M_{\mathrm{w}} / M_{\mathrm{n}}$ were estimated by size exclusion chromatography (SEC) using polystyrene standards to be 20200 and 1.56 , respectively. The content of amide unit, $7.70 \mathrm{mmol}$ equiv $/ \mathrm{g}$, was determined by the weight increased after the polymerization. The specific rotation of polyisocyanate after cleavage from PBI was $-5^{\circ}$, which was lower than that of the analogous polymer initiated from soluble pyrrolidine derivatives reported as $+416^{\circ}$ in the previous paper. ${ }^{17}$ Such difference might be caused by the steric effect of the supported resin, but the exact reasons have not been clarified yet. Thus, the conformation of polyisocyanate chain has been still ambiguous and seems not to be taken up as a proper reason for the discussion concerning the stereoselectivity of the aldol reaction in this work.

At first, the aldol reaction of benzaldehyde with two equiv of DMS enolate (1a), prepared from ethyl phenyl ketone, in the presence of $\mathrm{LiBr}$ catalyst was examined without any solvent (Table I). In the absence of PBI, the aldol reaction proceeded unsatisfactory to afford the corresponding product (2a) in only
$13 \%$ yield (Table I, entry 1). Whereas, the use of PBI, loaded the alkali metal salt catalyst before the reaction, was obviously improved the yield of 2a. The adduct 2a was obtained almost quantitatively, when $25 \mathrm{~mol} \%$ of $\mathrm{LiBr}$ to the aldehyde was employed and the molar ratio of [amide unit] to [ $\mathrm{LiBr}]$ was adjusted to be 10 (Table I, entry 2). From the examinations on the required amount of the catalyst, $12 \mathrm{~mol} \%$ of $\mathrm{LiBr}$ was found to be also effective for the reaction (Table I, entry 4). In comparison with the previous results using PDMA and PDMAG, where $25 \mathrm{~mol} \%$ of $\mathrm{LiBr}$ was required to give a satisfactory result. ${ }^{7}$ While, in the use of PDMA, PDMAG, and PBI, the ratio of [amide $] /[\mathrm{LiBr}]=10$ was preferable for the efficient reaction. These results indicated that the coordination abilities of PDMA and PBI were nearly equal. Therefore it was speculated PBI had the sufficient space to progress the reaction effectively owing to rigid polymer backbone. In addition, PBI and PDMA had the flexible polymer chains compared to the cross-linked PDMAG. This seemed to be one of the advantages for the effective solid solvents. Since the free polymeric amide units should trap the metal catalyst more effectively and provide the space for the substrates more readily than those in the rigid structure. As the result, it was indicated PBI was more appropriate sol- 


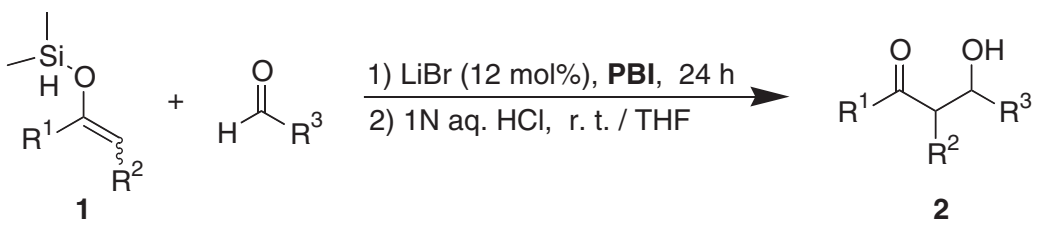

Scheme 4.

Table II. Aldol additions of DMS enolates with aldehydes in the Presence of $\mathbf{P B I}{ }^{\mathrm{a}}$

\begin{tabular}{cccclcccc}
\hline Entry & Enolate & $\mathrm{R}^{1}$ & $\mathrm{R}^{2}$ & \multicolumn{1}{c}{$\mathrm{R}^{3}$} & $\begin{array}{c}\text { Temp. } \\
\left({ }^{\circ} \mathrm{C}\right)\end{array}$ & Product & $\begin{array}{c}\text { Yield } \\
(\%)\end{array}$ & syn:anti $^{\mathrm{b}}$ \\
\hline 1 & $\mathbf{1 a}$ & $\mathrm{Ph}$ & $\mathrm{Me}$ & $\mathrm{Naph}$ & 40 & $\mathbf{2 b}$ & 35 & $59: 41$ \\
2 & $\mathbf{1 a}$ & $\mathrm{Ph}$ & $\mathrm{Me}$ & $\mathrm{Pr}$ & 60 & $\mathbf{2 c}$ & 43 & $55: 45$ \\
3 & $\mathbf{1 a}$ & $\mathrm{Ph}$ & $\mathrm{Me}$ & cyclohexyl & 60 & $\mathbf{2 d}$ & 29 & $52: 48$ \\
4 & $\mathbf{1 a}$ & $\mathrm{Ph}$ & $\mathrm{Me}$ & $t$ - $\mathrm{Bu}$ & 60 & $\mathbf{2 e}$ & trace & - \\
5 & $\mathbf{1 b}$ & $t-\mathrm{Bu}$ & $\mathrm{Me}$ & $\mathrm{Ph}$ & 40 & $\mathbf{2 f}$ & 45 & $73: 27$ \\
6 & $\mathbf{1 c}$ & \multicolumn{2}{c}{$\left(\mathrm{CH}_{2}\right)_{4}$} & $\mathrm{Ph}$ & 40 & $\mathbf{2 g}$ & 46 & $66: 34$ \\
7 & $\mathbf{1 d}$ & $\mathrm{Ph}$ & $\mathrm{H}$ & $\mathrm{Ph}$ & 40 & $\mathbf{2 h}$ & 37 & - \\
\hline
\end{tabular}

${ }^{\mathrm{a}} 1.0 \mathrm{mmol}$ of enolate, $0.5 \mathrm{mmol}$ of aldehyde $12 \mathrm{~mol} \%$ of $\mathrm{LiBr}$ for $24 \mathrm{~h}$, [amide unit] $/[\mathrm{LiBr}]=10$. ${ }^{\mathrm{b}}$ Determined by ${ }^{1} \mathrm{H}$ NMR.

id solvent for the reaction. However, the use of $5 \mathrm{~mol} \%$ of the catalyst resulted in the drastic decrease of the yield such as $15 \%$ even in the presence of PBI. In the aldol reaction, two equiv of benzaldehyde was required to obtain 2a in a good yield. As shown in the case using one equiv of aldehyde to DMS enolate, the yield of $2 \mathbf{a}$ decreased to $36 \%$ (Table I, entry 7 ).

Several metal halides were employed as the catalysts for the reaction to obtain the information about the activities, which related with PBI. The effects of anion species on the reaction were demonstrated by the facts that the yields of $\mathbf{2 a}$ decreased in order of $\mathrm{LiBr} \gg \mathrm{LiCl}>\mathrm{LiI}$ (Table I, entries 4, 9, and 10). Further, alkaline earth metal salts were used for the reaction as the catalysts. The combination of magnesium chloride $\left(\mathrm{MgCl}_{2}\right)$ with PBI was also effective to obtain 2a in the good yield such as $73 \%$ (Table I, entry 11). The yield of $\mathbf{2 a}$ decreased to $42 \%$ without PBI (Table I, entry 12). While, calcium chloride $\left(\mathrm{CaCl}_{2}\right)$, which was reported to be an effective catalyst for the analogous aldol reaction in DMF, hardly catalyzed the reaction under the conditions mentioned here (Table I, entry 13). ${ }^{8}$ In addition, the catalytic activity of other kind of catalyst, zinc bromide $\left(\mathrm{ZnBr}_{2}\right)$, was examined. The reaction proceeded to give $\mathbf{2 a}$ in the excellent yield over $92 \%$. However, no enhancement of the reaction brought by the presence of PBI was observed in the use of $\mathrm{ZnBr}_{2}$ (Table I, entries 14 and 15). $\mathrm{ZnBr}_{2}$ has been known to act as a Lewis acid in various reactions and should accelerate such aldol reaction. ${ }^{18}$ On the other hand, in the case of alkali metal salts and alkaline earth metal salts, anion species seemed to activate DMS enolate. Therefore, the amide units in PBI, which should coordinate the cation species and contribute to the formation of anion species, might be effective in those cases. In the utilization of the Lewis acid catalyst, the coordination by $\mathbf{P B I}$ is essentially useless to activate it. The results observed in the use of $\mathrm{ZnBr}_{2}$ seem to be explained by the above speculation, which is based on our thinking about the role of the solid solvent PBI.

The reaction system of $\mathrm{LiBr}$ and $\mathbf{P B I}$ was applied to the aldol reaction using various DMS enolates and aldehydes. The results of these solvent-free reactions were listed in Table II. The enolate $\mathbf{1 b}$ and $\mathbf{1 c}$ having cyclic and bulky tert-butyl substituent as $\mathrm{R}^{1}$, respectively, reacted with benzaldehyde to give the corresponding aldol products $\mathbf{2 f}$ and $\mathbf{2 g}$ in the moderate yields around $45 \%$ (Table II, entries 5 and 6 ). In the case of $\mathbf{1 d}$ having phenyl group as $\mathrm{R}^{1}$ and no alkyl substituent as $\mathbf{R}^{2}$, the yield of the aldol $\mathbf{2 h}$ was $37 \%$ (Table II, entry 7). The reactions using alkylaldehydes with 1a hardly gave the products. Therefore, the reaction temperature was raised from 40 to $60^{\circ} \mathrm{C}$ to obtain $2 \mathbf{c}$ in $43 \%$ yield (Table II, entry 2). However, the reactions of 1a with cyclohexylaldehyde and pivaraldehyde provided the corresponding aldols 2d or 2e in the lower yields such as $29 \%$ and trace (Table II, entries 3 and 4). These reactions might be affected by a steric hindrance, which should be an important factor especially in the polymeric environment. In the use of PBI, the site, holding the catalyst, assumed to be surrounded by the polyisocyanate chain. This basically makes the access of the bulky aldehydes to the site, where the enolate and the catalyst were also assembled, difficult in comparison with the 
less-bulky aldehyde. However, more detailed experiments using various substrates are required to clarify the critical factor on the steric problems, which relate to the configuration of polyisocyanate chain containing the alkali metal salt.

The stereoselectivity has been important in the investigation on the recent aldol reaction. However, the stereoselective aldol reaction was essentially difficult in the use of PBI with the alkali metal salt catalysts. All the aldols 2 obtained in this work showed only moderate syn-diastereoselectivity. Essentially, there were two considerable reasons to explain the results. One was the primarily doubt on the asymmetric polyisocyanate chain, which showed the low specific rotation as mentioned above. The other seemed to be main one that the aldol reaction does not progress through complete penta-coordinate siliconate transition state, which has been reported previously, ${ }^{19}$ and Lewis acidity of lithium cation on PBI is not strong enough to form the cyclic transition state. Meanwhile, in the use of trimethylsilyl (TMS) enolate, no corresponding product was obtained. This result might be caused by the decrement of Lewis acidity of silicon atom and/or the steric hindrance due to three methyl groups. Consequently, the role of PBI is thought to hold on cation species and form free anion species, which should activate DMS enolate. In other words, the relationship between PBI and the substrates might be neglect at least in a stereo determining step.

\section{SUMMARY}

In this report, we prepared the new solid solvent, PBI, and investigated its' effects on the aldol reaction using alkali metal salt as a catalyst. The results demonstrated that PBI was an effective matrix for the solvent-free aldol reaction. The structure containing amide units as the main chain in PBI was shown to be more favorable to hold alkali metal cation and afford free anion specie compared to polyacrylamide, since the use of PBI enable to decrease the required amount of the catalyst. The analogous aldol reaction using the metal salt catalysts has been reported to proceed quantitatively in the use of the liquid solvents such as DMF and DMAc. Consequently, the use of the solid solvents may not be favorable to pursue the efficiency of the reaction, but these like PBI could be collected readily after the reaction by a simple filtration and reused. Especially, in the consideration of an environmental problem, the combination of the low toxic metal catalyst such as alkali metal salt with the solid solvent seems to be a useful reaction system. The continuous investigations on the usages of designed solid polymer solvents are progressed and the results will be presented in near future.

\section{REFERENCES}

1. S. Kondo, Y. Inagaki, M. Ozaki, and K. Tsuda, J. Polym. Sci., Part A: Polym. Chem., 27, 3383 (1989).

2. K. Kahovec, M. Jelinkova, and V. Janout, Polym. Bull., 15, 485 (1986).

3. S. Kondo, M. Minafuji, Y. Inagaki, and K. Tsuda, Polym. Bull., 15, 77 (1986).

4. S. Kondo, Y. Inagaki, H. Yasui, and K. Tsuda, J. Polym. Sci., Part A: Polym. Chem., 29, 243 (1991).

5. S. Kondo, K. Ohta, R. Ojika, H. Yasui, and K. Tsuda, Makromol. Chem., 186, 1 (1985).

6. T. Oyama, J. Ozaki, and Y. Chujo, Polym. Bull., 38, 379 (1997).

7. S. Yamamoto, S. Hayashi, H. Morita, and O. Moriya, J. Polym. Sci., Part A: Polym. Chem., 42, 5021 (2004).

8. K. Miura, T. Nakagawa, and A. Hosomi, J. Am. Chem. Soc., 124, 536 (2002).

9. K. Miura, K. Tamaki, T. Nakagawa, and A. Hosomi, Angew. Chem., Int. Ed., 39, 1958 (2000).

10. L. Z. Yen and J. P. Mayer, J. Org. Chem., 68, 1161 (2003).

11. S. E. Denmark, K.-T. Wong, and R. A. Stavenger, J. Am. Chem. Soc., 119, 2333 (1997).

12. S. S. Labadie and J. K. Stille, Tetrahedron, 40, 2329 (1984).

13. S. Kobayashi, S. Nagayama, and T. Busujima, Tetrtahedron, 55, 8739 (1999).

14. F. Orsini, J. Org. Chem., 62, 1159 (1997).

15. C. Montignoul, M. J. Richard, V. Vigne, and L. Giral, J. Heterocycl. Chem., 21, 1489 (1984).

16. E. Hasegawa, K. Ishiyama, T. Horaguchi, and T. Shimizu, J. Org. Chem., 56, 1631 (1991).

17. Y. Okamoto, M. Matsuda, T. Nakano, and E. Yashima, Polym. J., 25, 391 (1993).

18. Y. Hayashi, M. Shoji, J. Yamaguchi, K. Sato, S. Yamaguchi, T. Mukaiyama, K. Sakai, Y. Asami, H. Kakeya, and H. Osada, J. Am. Chem. Soc., 124, 12078 (2002).

19. R. Noyori, K. Yokoyama, J. Sakata, I. Kuwajima, E. Nakamura, and M. Shimizu, J. Am. Chem. Soc., 99, 1265 (1977). 